\title{
Prevention strategies of most common female cancers
}

\author{
M Biamonte ${ }^{*}$, F Piccione \\ From de Senectute: Age and Health Forum \\ Catanzaro, Italy. 5-7 December 2009
}

Each year, the American Cancer Society (ACS) publishes a report summarizing its recommendations for early cancer detection, data and trends in cancer screening rates, and selected issues related to cancer screening.

\section{For endometrial cancer}

The ACS recommends that women at very high risk for endometrial cancer due to 1) known HNPCC genetic mutation carrier status; 2) a substantial likelihood of being a mutation carrier (ie, a mutation is known to be present in the family); or 3) the absence of genetic testing results in families with a suspected autosomal dominant predisposition to colon cancer should consider beginning annual testing for the detection of early endometrial cancer at age 35 years.

\section{For cervical cancer}

Screening for cervical cancer should begin approximately 3 years after first vaginal intercourse, but no later than age 21 years. Until age 30 years, women at average risk should receive either annual screening with conventional cervical cytology smears or biennial screening using liquid-based cytology. After age 30 years, a woman who has had 3 consecutive technically satisfactory Papanicolaou (Pap) tests with normal/negative results may choose to either undergo screening every 2 to 3 years.

\section{For ovarian cancer}

The guidelines recommend that women at average and increased risk should be informed about the high genetic risk. High-risk family histories with an elevated risk of developing ovarian cancer include $>2$ breast cancers and 1 or more cases of ovarian cancer at any age, $>3$ cases of breast cancer before age 50 years, sister pairs with cancers less than age 50 years, cases of breast

\footnotetext{
Centro Oncologico di Eccellenza. Unita' Operativa di Ginecologia Oncologica,
} Italy cancer occurring at or before age 40 years. Preventive Surgery ( bilateral salpingo-oophorectomy ) can reduce risk of ovarian and fallopian tube cancers for BRCA1, BRCA2 carriers and might improve survival rates in women carrying the BRCA1 or BRCA2 genes by about half a year to over two years.

\section{For vulvar cancer}

The guidelines recommend that women at average and increased risk should be informed about the risk factors: the majority of women diagnosed with vulvar cancer are older than 50. However, a significant percentage (15\%) of women under 40 develop vulvar cancer. Generally, vulvar cancer in younger women is associated with HPV infection and smoking; women with lowered immune systems have a higher risk of developing vulvar cancer; about $4 \%$ of women with lichen sclerosus develop vulvar cancer.

Published: 19 May 2010

doi:10.1186/1471-2318-10-S1-L5

Cite this article as: Biamonte and Piccione: Prevention strategies of most common female cancers. BMC Geriatrics 2010 10(Suppl 1):L5.

Submit your next manuscript to BioMed Central and take full advantage of:

- Convenient online submission

- Thorough peer review

- No space constraints or color figure charges

- Immediate publication on acceptance

- Inclusion in PubMed, CAS, Scopus and Google Scholar

- Research which is freely available for redistribution

Submit your manuscript at www.biomedcentral.com/submit 